\title{
Online Content Publishing and Revenue Sharing: Strategies for Success
}

\author{
Vinayak Nair ${ }^{1}$ Sanjay Mahalingam ${ }^{2}$ \\ ${ }^{1}$ (Department of Management Studies, Sri Sathya Sai Institute of Higher Learning, India) \\ ${ }_{2}^{2}$ (Department of Management Studies, Sri Sathya Sai Institute of Higher Learning, India)
}

\begin{abstract}
Internet is ubiquitous today and a part of almost every human endeavour. Web 2.0 has ushered in an era of widespread participation and communication on the internet. This has given rise to User Generated Content (UGC) which is created, accessed, modified and uploaded by the users. This has opened up many avenues; one among them is online content publishing with revenue sharing. This study is an attempt to study this nascent industry and get insights into their business models and make strategy recommendations for success. We prepared four case studies, three of the dominant players in the industry and one platform started and run by the authors themselves. An online survey was also conducted to study the perception of the customers. We recommend more promotional efforts to increase awareness, greater mobile platform optimization, advanced SEO strategies, multiple language support and easier and more transparent revue sharing process.
\end{abstract}

Keywords: Online Content Publishing, Hubpages, Squidoo, Strategy, Web 2.0, Revenue Sharing, User Generated Content,

\section{INTRODUCTION}

In the early days of the Internet, (the period before 1990's) the end users played no role in contribution of website content. They did not participate in the addition, modification or creation of content. The World Wide Web (WWW) at this stage was referred to as web 1.0. It was characterized by websites that were static in nature, a set of web pages connected through web links . Gradually, primarily due to technological developments and innovations, web 1.0 gave way to a new paradigm, commonly referred to as web 2.0. Web 2.0 has several remarkable features. It has created a participatory culture by providing the end user with tools and processes to actively participate in content creation. It has enabled the users to contribute content (e.g.: YouTube), moderate and rate content (e.g.: rating systems in blogs and forums), post comments (e.g.: blogs, forums) and request for content (e.g.: Yahoo answers). Web 2.0 has also paved the way for the social web. The easy-to-use and intuitive user interfaces of web 2.0 combined with its emphasis on user involvement has been instrumental in the rise of social networking sites like Facebook and Twitter.

Web 2.0 has enabled several exciting services to grow and has opened up new avenues in the Internet. Among the many possibilities that have arisen, one of them is the ability of internet users to upload content to internet with ease. The content, they thus create, can be accessed, viewed and downloaded by other internet users around the globe. The sharing of content has become an easy task. This has resulted in an explosive growth of User Generated Content (UGC) on the web. The backbone of an online content publishing platform is UGC.

\section{Online Content Publishing and Revenue Sharing: An Evolution}

In 1997 a service called Slashdot was started as one of the first platforms to allow users to publish content online. The service was focused on technical oriented content and didnot offer revenue sharing. In 1998 Drew Curtis started Fark.com to share news items with his friends but gradually it grew into a big User Generated Content website and was incorporated as Fark Inc. in 2008 ${ }^{1}$. Year 2001 saw the arrival of the free online encyclopaedia, Wikipedia. Wikipedia does not offer revenue sharing but the user activity and user involvement have risen over the years and it has expanded to other languages besides English. For the first time revenue sharing was offered to content publishers online by Google Answers, which would pay users to answer questions posed by other users. The service was closed down in 2006 by Google but the content previously generated by users is still available at answers.google.com. One might say the online content publishing industry with revenue sharing really just started in 2005 with the birth of Squidoo.com. Squidooallowed anyone with an email ID to register for free, make money by posting their ideas, thoughts and opinions using a user friendly interface. In 2006, many more services entered the market which allowed users with an email ID to publish content while offering them a share of revenues. They include Hubpages.com, Xomba.com, Helium.com etc. In 2007, Youtube.com began to share its revenue with premium users and later in 2009, the program was expanded to include all users. The period after 2007 is characterized by entry of large number of players who shared ad 
revenue with users. Most of them were sharing revenue by integrating a third party advertisement program called AdSense, an advertising network owned by Google.

\section{RESEARCH OBJECTIVES}

The primary objectives of this nine month long research project were as follows

- To understand the business models of the online content publishing and revenue sharing platforms.

- To gain an insight into the current strategies being followed by players in this industry

- To suggest strategies for success in the online content publishing and revenue sharing industry

\section{LITERATURE REVIEW}

The purpose of this literature review is to briefly explore the current published literature on user generated content, its impact on internet users, internet business models, monetization models, internet customer behaviour and strategies adopted by firms in the online content publishing with Revenue Sharing industry.

Ever since Squidoo came up with a model for user generated content featuring revenue sharing, the industry has been witnessing entry of new players (Hubpages, Xomba, YouTube partner program etc.) The last decade has witnessed several other players which were created with open source software. Free and Open source software reduced the cost of entering the field. New players emerged which copied the business model of existing players. In fact a quick Google search will produce a list of over 100 revenue sharing websites using Google AdSense. ${ }^{2}$

The arrival of Web 2.0 and improvements in connectivity and technology there has been an explosive growth in User Generated Content (UGC.) ${ }^{3}$ which have led to online content publishing and virtual communities. Elise Porter et al (2013) ${ }^{4}$ examine value creation in virtual communities. They discuss how companies can derive value by investing in maintaining virtual communities and gain from their opinions and ideas. Another important off shoot of web 2.0 that companies can use to create value for themselves is crowd sourcing. Daren C. Brabham $(2008)^{5}$ defines crowdsourcing as "an online, distributed problem-solving and production model". Schroeder $(2011)^{6}$ defines crowd sourcing as "milking the masses for inspiration". Kevin J Boudreg et al $(2013)^{7}$ warn that companies that fail to use crowdsourcing miss out on a cost-effective way to kick-start innovation. According to them crowds are motivated by a desire to learn new things and gain reputation in a community, which can be harnessed as a low cost means of problem solving.

Spending time online is clearly replacing watching TV as the favourite pastime for the $\mathrm{X}$ and $\mathrm{Y}$ generation (JiyoUng Cha, 2013). This is one the important reasons why the demand for content marketing is growing rapidly. On an average content marketing majors are allocating as much $13 \%$ of their budgets to content creation and $58 \%$ of that is being outsourced. So clearly there is amutual relationship where a third party publisher can add value to these content marketing majors by providing high quality content and also earn revenue (Michael J. LoPresti, 2013) ${ }^{9}$

Why do people publish online? According to Qian Tang et al (2012) ${ }^{\mathbf{1 0}}$ they do so for exposure, earning money and enhancing their reputation among peers. Several platforms that receive large amounts of user generated Content fulfil these needs of their users. Bateman et al (2011) ${ }^{\mathbf{1 1}}$ state that online users who consume or create content are driven by three main commitments-"Need based" commitments, driving them to consume content, "Affection-based" commitments drives them to posting replies and "obligation-based" commitments drives them to moderation in content creation.T. E. Dominic Yeo (2012) ${ }^{\mathbf{1 2}}$ states that certain personality traits (he calls it the "Big 5" personality traits) mainly determine what motivates a user to publish online.

Why do firms offer revenue sharing? For many websites like YouTube, the business model is based on user contributed content. They attract advertisers based on the activity of the user. Here, the firm has a strong need to motivate the user. They offer revenue sharing to motivate the user to contribute high quality content. They consider revenue sharing as an incentive for motivation Qian Tang et al (2012).

Michael rappa $(2013)^{\mathbf{1 3}}$ identifies and places the internet business models into these categories: Brokerage model (makes money by facilitating transaction, getting buyer and seller together), Advertising model (Thrown open to users and money made by posting ads on the virtual property), Affiliate model (makes money by directing the user to take a certain action, usually a purchase), Infomediary model (money made through information derived about the user), Manufacturer (direct) model (making money by cutting down layers between manufacturer and the consumer), Subscription model (users are charged money, a fee for a service), Utility model (the user pays for the service used), Merchant model (merchants sell through internet auction) and Community model.

There are three common ways used to monetize a website Vinayak Nair $(2011)^{14}$ : Selling a product or service using the website, affiliate programs (direct website visitors to another website and earn commission whenever the referred user performs a desired action at the website) and posting advertisements. A website could create its own algorithms or adopt an advertising program like Google AdSense. Google AdSense displays 
advertisements on publisher's website and pays them every time a web surfer clicks on the ads, thus helping the publisher of a website to monetize his web property.

\section{RESEARCH METHODOLOGY AND SCOPE}

In this section we discuss the researchmethodology of, the scope of, and the need for the study.The study was limited to players in the online content publishing industry that

- offer free registration to everyone,

- $\quad$ are community based and

- allow content creators to earn money by publishing content (share revenue).

Using secondary sources of data including (but not limited to) academic and non-academic journals, articles, websites, blogs, forums and the authors'own domain knowledge and experience etc. detailed case studies were developed for three dominant playersin this industry. They are Hubpages.com, Xomba.com and Squidoo.com. A fourth case study was prepared on a platform started and managed by the authors themselves, Paidwriter.net, giving them an unique vantage point advantage and a first-hand insight into the challenges in profitably running such a platform. The case studies were analysed to understand the business models of and strategies followed by the players in the industry.

After gaining an insight into the industry with the case studies, we conducted an online survey with a semi-structured questionnaire titled - Survey to Measure Attractiveness of Internet Content Publishing Platforms. The questionnaire was also adaptive (the next question depended on the previous answer), enabling us to more efficiently get the information and making the process brief for the respondents. Respondents were sought randomly from online forums like Facebook (friends and friends of friends), blogs etc. the responses were analysed mainly for aggregate information. A total of 876 (Eight Hundred and Seventy Six) responses were received. Posting the survey on the internet ensured that the respondents are people who have access to and use the internet.

Using more than one source of data and methodology helped us achieve convergence and triangulation, enabling validation of our findings through cross verification from multiple sources.

\subsection{THE BUSINESS MODEL}

\section{FINDINGS}

There are 2 types of customers for the business; the content creator and the content consumer. The content creator is the one who posts content for the website. They sign up for free and add value to the business by posting content. They are motivated by revenue sharing (economic rewards), recognition and a medium to express their thoughts and ideas. The content consumer on the other hand, is the source of revenue generation; a website generates revenue by monetizing the website traffic generated by the content consumer. They are driven by a need for information and consumption of knowledge and ideas.

For revenue sharing, companies use two modelsfor distribution of shared revenue.

- The website publisher pays the content creator directly from the revenue generated from the content. This model is used by Squidoo.com

- In the second model, the publisher does not pay the content creator directly. The content creator has to create an account with affiliate advertising programs like, Google AdSense, or third part e-commerce platforms like Amazon, eBay etc. The content webpages created, host appropriate advertisements, selected by the affiliate program's algorithm. A percentage of the revenue thus generated is transferred to the content creator's AdSense account.

5.2 SQUIDOO.COM AND HUBPAGES.COM- AN ILLUSTRATION:To better understand the business models we offer an illustration of the contrasting models followed by Squidoo.com and Hubpages.com.

- Squidoo.com has two kinds of customers- the content creator and the website visitor. The content creator signs up with Squidoo with a simple registration process, free of cost. He can then post content on various topics. These content webpages are called Lens. Then there is the website visitor who comes to the site seeking information who is the source of the company's revenue. Squidoo places advertisements (through Google Ad sense) and also referral links to ecommerce websites (Amazon.com, Ebay.com) in the lenses. Whenever a website visitor visits a particular page in Squidoo and clicks on the advertisement or follows the referral to make a purchase Squidoo generates revenue. 50\% of the revenuethus generated by Squidoo is shared with the creator of the content page (lens). The amount is not given to the Lens Masters(content creators) directly, but put in a pool. The Lens Masters get paid depending on the performance of the Lens. To evaluate the performance Squidoo uses an in-house ranking system called "LensRank". 
- Hubpages.com uses a similar model but a different process for shared revenue distribution. Content creators sign up for free and post content on pages that Hubpages calls Hubs. Hubpages places ads on these Hubs using Google AdSense, and other affiliate programs. When visitors click on or follow these ads to make a purchase,Hubpages makes money. $60 \%$ of that money is shared with the owners of the Hubs from where the referral originated. This is done by crediting the AdSense account of the Hub owner.

\subsection{SOME OTHER FINDINGS FROM THE CASE STUDIES}

\begin{tabular}{|c|c|}
\hline Positioning & $\begin{array}{l}\text { All these platforms, namely, Hubpages.com, Squidoo.com, Xomba.com and Paidwriter.net are positioned } \\
\text { as revenue sharing content publishing platforms. }\end{array}$ \\
\hline Success Factors & $\begin{array}{l}\text { - Number of visitors: The larger the number of visitors, greater the revenue generated, which } \\
\text { depends on the quality of the published content } \\
\text { Traffic received from search engines: Search engines play a vital role in generating inbound } \\
\text { traffic. So strategies for maximizing search engine visibility are important } \\
\text { - Content creator motivation: The quantity and quality of content created by registered users adds } \\
\text { value to the website visitor. Also individual content creator's efforts to promote his work add } \\
\text { up to massive gain for the platform. }\end{array}$ \\
\hline $\begin{array}{l}\text { Lifelong income } \\
\text { opportunity }\end{array}$ & $\begin{array}{l}\text { The content creator can earn revenue whenever website visitors visit his content pages in these platforms. } \\
\text { The revenue is generated by the interaction happening between website visitors and advertising/affiliate } \\
\text { programs. The content continues to generate income for him as long as it remains published in the } \\
\text { platform. }\end{array}$ \\
\hline $\begin{array}{l}\text { Free Access to the } \\
\text { visitor }\end{array}$ & Content consumers are given free access to content \\
\hline Monetization & It is done by posting advertisements on the web pages using advertisements and affiliate programs \\
\hline $\begin{array}{l}\text { Rewarding } \\
\text { performance }\end{array}$ & $\begin{array}{l}\text { Squidoo and Xomba run contests to promote user activity. Further, they recognize the contribution of } \\
\text { content creators by recognizing them with various virtual awards that are displayed in their profile pages. }\end{array}$ \\
\hline $\begin{array}{l}\text { Revenue sharing } \\
\text { process }\end{array}$ & $\begin{array}{l}\text { The process through which the user needs to go through to be eligible for revenue sharing is complex. } \\
\text { Users who are amateurs may find it to be difficult and may leave the platform. }\end{array}$ \\
\hline $\begin{array}{l}\text { Content } \\
\text { Ownership }\end{array}$ & The content published is almost always owned by the creator of the content and not by the website \\
\hline Mobile Readiness & $\begin{array}{l}\text { From the web traffic stats of Squidoo and Hubpages generated by Quantcast.com, it is evident that their } \\
\text { user base is showing an increase in mobile phone internet users. i.e., growing number of people, access } \\
\text { these platforms through mobile phones. But they are not optimized for mobile phones. They display the } \\
\text { same layout when the content consumer uses a pc and mobile phone. }\end{array}$ \\
\hline Language & $\begin{array}{l}\text { All these sites permit publishing content in English language only. Content in any other languages is not } \\
\text { permitted }\end{array}$ \\
\hline
\end{tabular}

\subsection{FINDINGS FROM THE ONLINE SURVEY}

An online survey was conducted to measure the attractiveness of and perceptions about internet content publishing platforms. We received 876 (Eight Hundred and Seventy Six)completed responses from several countries including India, United States, Australia, Singapore, Qatar, United Kingdom and Kuwait.Some salient aggregate findings from the online survey are discussed in this section.

- $65 \%$ of the respondents were students. $79 \%$ of the respondents spent time online frequently or very frequently (Fig. 1).

- A substantial section (29\%) of the respondents used mobile devices like Mobile phones and Tablets to access the internet. (Fig. 2) 
- $38 \%$ of the respondents, despite spending considerable time online were not aware of the possibility of earning revenue by publishing online. (Fig. 3)

- $56 \%$ of the respondents have heard of the concept but do not know much, 30\% know about online publishing well but haven't participated in the same. Only $14 \%$ of the respondents are a part of one of the online publishing platform. (Fig. 4)

- Among the respondents who are not a part of any online publishing platform, the main reasons for not doing so appear to be lack of awareness (38\%), Lack of interest (28\%) and lack of belief that they can make money on these platforms (20\%). (Fig. 5)

- Among the respondents who are a part of one of the platforms, the most popular appears to be Blogger (31\%), followed by Hubpages (26\%), Xomba (16\%), Squidoo (11\%) and Wordpress (11\%). (Fig. 6)

- Among the respondents who are a part of one of the platforms, $71 \%$ visit their content pages very often (at least once a week).

- Among the respondents who are a part of one of the platforms only $28 \%$ seem to be satisfied with their platform. (Fig. 7)

- Among the respondents who were once publishing online but stopped later (5\%), the most prevalent reason for stopping appears to be loss of interest and absence of monetary earning as expected. (Fig. 8)

- Respondents who are publishing online were asked to rate features that they desire in their online publishing platform. The features which got the highest average rating were, in order of importance

1. Monetary revenue

2. Ease of usage for writing / publishing / archiving / sharing

3. Contests / special offers

4. Recognition

5. Wide readership and timely feedback

- The respondents who were interested in publishing online were asked to rate the reasons that motivate them the most. The reasons which were most important (average score) are mentioned below in order of importance

1. Creative outlet/Joy of writing

2. Time pass

3. Monetary revenue

4. Feedback / recognition

5. Extensive readership and reach

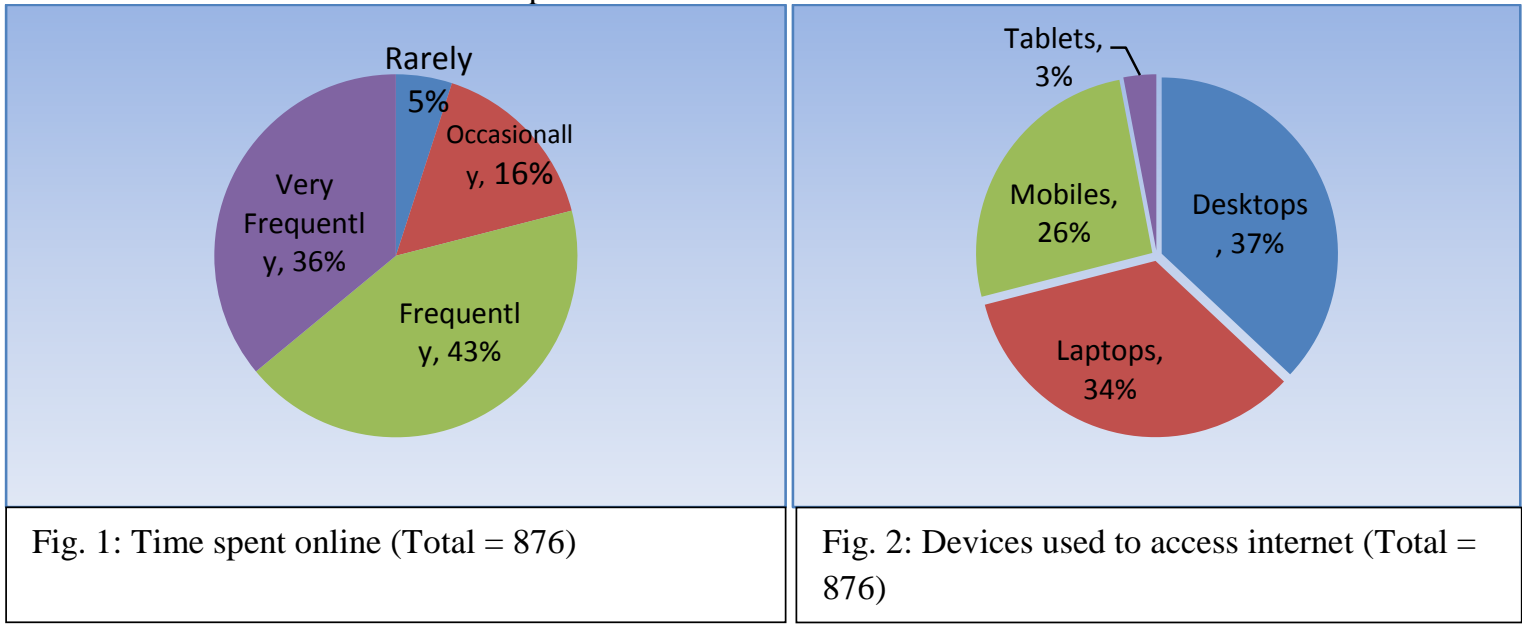



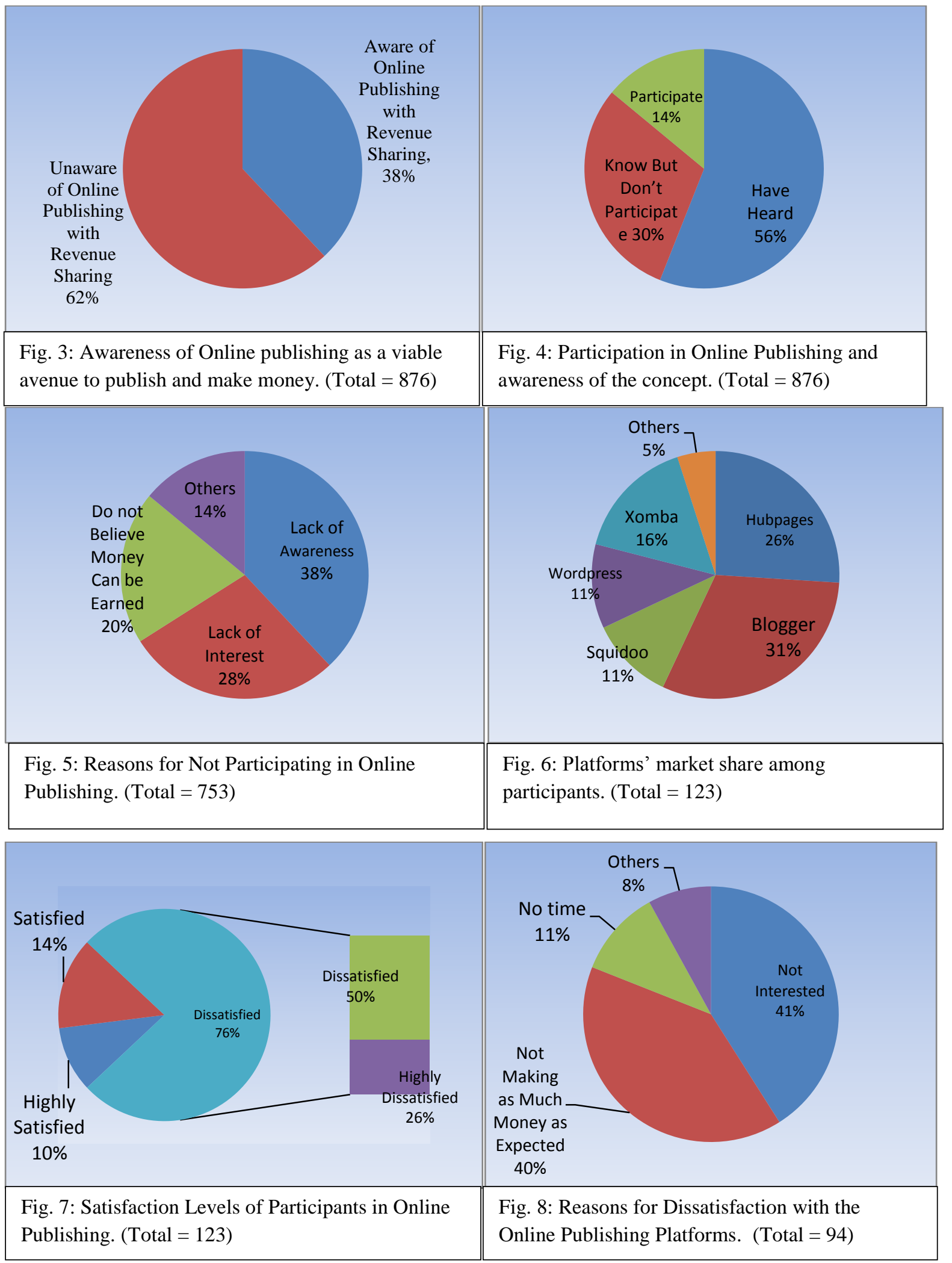

\section{RECOMMENDATIONS}

In this section we draw on some of the important finings of the study and discuss the implications for companies in the online publishing industry and suggest some strategies for success

1. Increasing Awareness:A sizable percentage of the internet population is either totally unaware of the possibilities of earning money by publishing online or have a very rudimentary awareness of the concept. 
This is a missed opportunity. We recommend that companies expend efforts to increase awareness about their offerings, possibly by running promotional activities on social networks or running contests for content creators and offer rewards for existing users for making referrals

2. Trust Building: Lack of trust prevents many potential users from enrolling for the service. Trust can be enhanced by timely payment of shared revenue, taking strict measures to prevent spam content and following well defined procedures for dealing with incidences of copyright violations .The procedure should be communicated clearly to users and the same should be published on the website.

3. Revenue Sharing Process: We found that the revenue sharing process is complex for an average internet user who possesses minimum internet skills. The user usually needs to sign up with a third party to be eligible for payment. (They either require the User to sign up with an advertiser like Google AdSense or online money transfer service like PayPal for getting paid). If the users don't have the account with third party, they can't monetize their content. The complexity may prevent many users from publishing content especially if they are not able to get approved by the third party. We recommend the firms should eliminate complicated steps in the process. They should make the whole process simple. The whole process of dealing with advertisers should be taken care of by the platform. All the user should need to do is to create an account with the platform, submit their address and/or bank account number and publish content.

4. Mobile Platform optimization: Many of the platforms are not optimized for mobile devices including mobile phones, tablets etc. The platform therefore, fails to deliver satisfactory user experience in terms of layout and navigation to the users of mobile devices. We recommend the following strategies.

- Optimize the website (platform) for mobile phone access by creating a mobile friendly version

- Create apps (official) to give direct access to these platforms from users of mobile operating systems like Android, iOS, Blackberry and Windows. This will lead to other opportunities like ensuring that the user is able to access the service from his mobile phone anytime

- The apps store i.e. the market where mobile phone apps are listed already receives huge amount of traffic. By having an app listed in the store, platform can receive exposure to the brand and increase awareness.

- By capturing the location of the user using the app, location specific content can be delivered to the user

5. Extending Alternative Language Support:At present almost all platforms only allow English content. A huge potential market for content in native languages is getting missed out. By offering content creation possibilities in at least some major non-English languages of the world like French. Chinese, Hindi etc. and offering service to translate the current content into these languages, a huge untapped market can be reached out.

\section{CONCLUSION}

A nine-month log project to study the online content publishing industry wassuccessfully concluded. Business models were analysed and recommendations were made. The study restricted itself to the companies that offer revenue sharing. There are many other business models where online publishing platforms do not offer any revenue sharing but are still very successful in terms of membership. Those business models need further study.

\section{REFERENCES}

[1] Wikipedia. 2013. Web 1.0. [online] Available at: http://en.wikipedia.org/wiki/Web_1.0 [Accessed: 9 Nov 2013].

[2] Adams, K. 2013. A List Of 23 Google AdSense Revenue Sharing Sites 2013/2014 | The Konsult Hub. [online] Available at: http://www.thekonsulthub.com/general-articles/a-list-of-19-google-AdSense-revenue-sharing-sites-201314/ [Accessed: 10 Dec 2013].

[3] George, Carlisle E. and Scerri, Jackie, Web 2.0 and User-Generated Content: Legal Challenges in the New Frontier (2007). Journal of Information, Law and Technology, Vol. 2, 2007. Available at SSRN: http://ssrn.com/abstract=1290715

[4] Porter, Constance Elise, Sarv Deva Raj, and Daewon Sun. "A Test of Two Models of Value Creation in Virtual Communities." Journal of Management Information Systems / Summer 2013 30.1 (2013): 261-92

[5] Daren C. Brabham1. (2008). Crowdsourcing as a Model for Problem Solving An Introduction and Cases. Convergence: The International Journal of Research into New Media Technologies. 14, 75-90.

[6] Schröder, S, 2011. A business model approach to Web 2.0. PHD. Denmark: Copenhagen Business School.

[7] Kevin J. Boudreau,Karim R. Lakhani. (2013). USING THE CROWD AS AN INNOVATION PARTNER. Harvard Business Review. April 2013, 62-69. 
[8] Jiyoung Cha. (2013). Do Online Video Platforms Cannibalize Television? How Viewers Are Moving from Old Screens to New Ones. JOURNAL OF ADVERTISING RESEARCH. 53, 71-81.

[9] Michael J. LoPresti. (2013). Growth of Content Marketing Provides Opportunity for Publishers. ECONTENT [online]. 8 10.Available from: http://www. E c o n t e n t m a g. c o m.

[10] Qian Tang, Bin Gu, and Andrew B. Whinstonon. (2012). Content Contribution for Revenue Sharing and Reputation in Social Media: A Dynamic Structural Model. Journal of Management Information Systems / Fall 2012. 29, 49-75.

[11] Bateman, P. J., Gray, P. H., \& Butler, B. S. (2011). The Impact of Community Commitment on Participation in Online Communities. Information Systems Research, 22(4), 841-854. doi:10.1287/isre.1090.0265

[12] T. E. Dominic Yeo. (2012). Social-Media Early Adopters Don't Count How to Seed Participation in Interactive Campaigns by Psychological Profiling of Digital Consumers. JOURNAL OF ADVERTISING RESEARCH. September 2012, 297-307

[13] Rappa, P. 2013. Business Models on the Web | Professor Michael Rappa. [online] Available at: http://digitalenterprise.org/models/models.html [Accessed: 25 Nov 2013].

[14] Nair,Vinayak G ( 2011) How To Make Money Online : Expert Advice, Kindle Edition edn., U.S.: Amazon Digital Services, Inc. 